\title{
Review Article \\ Colorectal Cancer Screening in Average Risk Populations: Evidence Summary
}

\author{
Jill Tinmouth, ${ }^{1,2,3,4,5}$ Emily T. Vella, ${ }^{6}$ Nancy N. Baxter, $, 4,7,8$ \\ Catherine Dubé, ${ }^{1,9}$ Michael Gould, ${ }^{10,11}$ Amanda Hey, ${ }^{12}$ Nofisat Ismaila, ${ }^{13}$ \\ Bronwen R. McCurdy, ${ }^{1}$ and Lawrence Paszat ${ }^{2,3,4}$ \\ ${ }^{1}$ Prevention and Cancer Control, Cancer Care Ontario, Toronto, ON, Canada \\ ${ }^{2}$ Department of Medicine, Sunnybrook Health Sciences Centre, Toronto, ON, Canada \\ ${ }^{3}$ Institute for Clinical Evaluative Sciences, Toronto, ON, Canada \\ ${ }^{4}$ Institute of Health Policy, Management and Evaluation, Dalla Lana School of Public Health, University of Toronto, \\ Toronto, ON, Canada \\ ${ }^{5}$ Department of Medicine, University of Toronto, Toronto, ON, Canada \\ ${ }^{6}$ Program in Evidence-Based Care, Cancer Care Ontario, Hamilton, ON, Canada \\ ${ }^{7}$ Department of Surgery, St. Michael's Hospital, Toronto, ON, Canada \\ ${ }^{8}$ Li Ka Shing Knowledge Institute, St. Michael's Hospital, Toronto, ON, Canada \\ ${ }^{9}$ Department of Medicine, Division of Gastroenterology, University of Ottawa, The Ottawa Hospital, Ottawa, ON, Canada \\ ${ }^{10}$ William Osler Health Centre, Etobicoke, ON, Canada \\ ${ }^{11}$ Vaughan Endoscopy Clinic, Vaughan, ON, Canada \\ ${ }^{12}$ Northeast Cancer Centre Health Sciences North/Horizon Santé-Nord, Sudbury Outpatient Centre, Sudbury, ON, Canada \\ ${ }^{13}$ American Society of Clinical Oncology, Alexandria, VA, USA
}

Correspondence should be addressed to Jill Tinmouth; jill.tinmouth@sunnybrook.ca and Emily T. Vella; ccopgi@mcmaster.ca

Received 1 April 2016; Accepted 29 June 2016

Academic Editor: Mark Borgaonkar

Copyright (C) 2016 Jill Tinmouth et al. This is an open access article distributed under the Creative Commons Attribution License, which permits unrestricted use, distribution, and reproduction in any medium, provided the original work is properly cited.

Introduction. The objectives of this systematic review were to evaluate the evidence for different CRC screening tests and to determine the most appropriate ages of initiation and cessation for CRC screening and the most appropriate screening intervals for selected CRC screening tests in people at average risk for CRC. Methods. Electronic databases were searched for studies that addressed the research objectives. Meta-analyses were conducted with clinically homogenous trials. A working group reviewed the evidence to develop conclusions. Results. Thirty RCTs and 29 observational studies were included. Flexible sigmoidoscopy (FS) prevented CRC and led to the largest reduction in CRC mortality with a smaller but significant reduction in CRC mortality with the use of guaiac fecal occult blood tests (gFOBTs). There was insufficient or low quality evidence to support the use of other screening tests, including colonoscopy, as well as changing the ages of initiation and cessation for CRC screening with gFOBTs in Ontario. Either annual or biennial screening using gFOBT reduces CRC-related mortality. Conclusion. The evidentiary base supports the use of FS or FOBT (either annual or biennial) to screen patients at average risk for CRC. This work will guide the development of the provincial CRC screening program.

\section{Introduction}

Canada has one of the highest rates of colorectal cancer (CRC) in the world, with an estimated 25,100 cases in 2015
$[1,2]$. CRC is also one of the leading causes of cancer-related death for men and women combined in Canada, with an estimated 9300 deaths in Canada in 2015. However, if CRC is found in its early stages, there is a $90 \%$ chance that it can 
be cured [1]. Cancers detected through screening tend to be earlier stage compared with cancers detected outside of screening [3-6]. In 2008, Ontario launched its CRC screening program, which offers screening to Ontarians aged 50 to 74 . People at average risk are offered the guaiac fecal occult blood test (gFOBT) once every two years, while people at increased risk, defined as having one or more first-degree relatives with CRC, are offered colonoscopy. In 2013, approximately 58.5\% of Ontarians were up-to-date with CRC screening tests [7].

In light of emerging evidence, the provincial CRC screening program is seeking guidance for CRC screening of average risk individuals in Ontario. Cancer Care Ontario's Prevention and Cancer Control portfolio and the Program in Evidence-Based Care (PEBC) developed this evidentiary base to help inform the CRC screening program in Ontario, ColonCancerCheck.

The evidence supporting primary screening tests for CRC, ages of initiation and cessation for CRC screening, and screening intervals for selected CRC screening tests in people at average risk for CRC was systematically reviewed to develop this evidentiary base. Below, the methods and key findings of the systematic review are summarized. The full evidentiary base is available online [8].

\section{Systematic Review Objectives}

The purpose of this systematic review is to evaluate the existing evidence concerning screening of adults at average risk for CRC in the context of an organized, population-based screening program. The main objectives are to identify the following:

(i) The benefits and harms of screening in this population.

(ii) The optimal primary CRC screening test(s) for this population.

(iii) The appropriate ages of initiation and cessation for screening in this population.

(iv) The intervals at which people at average risk should be recalled for CRC screening.

\section{Target Population}

The target population includes primary care providers, endoscopists, policy-makers, and program planners in Ontario.

\section{Research Questions}

4.1. Primary Research Question. Primary Research Question is as follows:

(1) How do different screening tests, individually or in combination, perform in average risk people in preventing CRC-related mortality or all-cause mortality or in decreasing the incidence of CRC? Secondary outcomes include the detection of cancer or its precursors, screening participation rate, adverse effects of tests, and test characteristics, such as sensitivity, specificity, positive predictive value, negative predictive value, and proportion of false-positives or of false-negatives.

4.2. Secondary Research Questions. Secondary Research Questions are as follows:

(1) What are the appropriate ages of initiation and cessation for screening in people at average risk for CRC? Is there a relationship between age and the effectiveness of CRC screening?

(2) What are the appropriate intervals between CRC screening tests (by test)? Is there a relationship between screening intervals and the effectiveness and risks of screening?

\section{Methods}

The authors of this evidentiary base (working group) consisted of one primary care physician, one colorectal surgeon, one expert in public health screening, one policy analyst from the Ontario CRC screening program, two methodologists, and three gastroenterologists. The $\mathrm{PEBC}$, a provincial program of Cancer Care Ontario, is supported by the Ontario Ministry of Health and Long-Term Care. All work produced by the PEBC and any associated programs is editorially independent from the ministry.

A two-stage method was used. It is summarized here and described in more detail as follows:

(1) Search and evaluation of existing systematic reviews: if existing systematic reviews were identified that addressed the research questions and were of reasonable quality, then they were included as a part of the evidentiary base.

(2) Original systematic review of the primary literature: this review focused on areas not covered by existing and accepted reviews.

5.1. Literature Search Strategy. A systematic search was conducted in OVID MEDLINE (2006 to September 3, 2014), EMBASE (2006 to September 3, 2014), the Cochrane Library (Issue: 2-4, October 2013), and the American Society of Clinical Oncology (ASCO) conference proceedings (2009 to 2013). Details of the literature search strategy can be found online [8].

5.1.1. Study Selection Criteria and Protocol. Systematic reviews were included if

(i) they addressed at least one of the research questions,

(ii) they evaluated randomized or nonrandomized control trials of asymptomatic average risk subjects undergoing CRC screening,

(iii) the literature search strategy for the existing systematic review was reproducible (i.e., reported) and appropriate,

(iv) the existing systematic review reported the sources searched, as well as the dates that were searched. 
Identified systematic reviews were assessed using the Assessing of Methodological Quality of Systematic Reviews (AMSTAR) tool [82]. In cases where multiple systematic reviews were identified for a particular outcome, only evidence from the most recent systematic review with the highest quality was used in the evidence base. The literature was searched for new primary studies published after the end search date of included systematic reviews. Individual study quality from the studies included in the systematic reviews as well as any new primary studies was assessed in order to complete the Grading of Recommendations, Assessment, Development and Evaluations (GRADE) tables for risk of bias [9].

If no existing systematic review was identified for a given test or question, or if identified reviews were incomplete, a systematic review of the primary literature was performed. Articles in reference lists from included studies were also searched. The scope of the primary literature review was tailored to address the gaps in the incorporated existing systematic reviews (e.g., subject areas covered and time frames covered). The criteria for the primary literature are described as follows.

Inclusion Criteria. Inclusion criteria are as follows:

(1) Randomized controlled trials (RCTs) (primary research question and secondary research questions 1 and 2) that could be identified directly from the search or from reference sections of systematic reviews.

(2) Cohort/case-control studies, minimum study size $n=$ 30 (secondary research questions 1 and 2).

(3) Evidence from nonrandomized prospective comparative studies with historical or contemporaneous controls, with the consensus of the working group, when there were gaps in available evidence from RCTs.

(4) Studies preferred with asymptomatic average risk subjects and population-based studies that did not oversample adults with symptoms of CRC or a family history of CRC which were also considered acceptable.

(5) For conference abstracts: RCTs (all questions).

(6) The following screening tests considered for inclusion:

(i) fecal-based tests including gFOBT, fecal immunochemical test (FIT), stool DNA panel (stool DNA), and fecal M2-PK,

(ii) blood tests $\left(\right.$ Cologic $^{\circledR}$, ColonSentry $^{\circledR}$, mSEPT9, metabolomics, and hydroxylated polyunsaturated long chain fatty acids),

(iii) endoscopic tests including flexible sigmoidoscopy (FS), colonoscopy, and capsule colonoscopy,

(iv) radiological tests including double-contrast barium enema (DCBE) and computed tomography colonography (CT colonography).
Exclusion Criteria. Exclusion criteria are as follows:

(1) Letters, comments, or editorials.

(2) Studies that included a population enriched with subjects with symptoms of CRC or a family history of CRC.

(3) Nonsystematic reviews.

(4) Non-English-language publications.

One of the two reviewers (NI and EV) independently reviewed the titles and abstracts resulting from the search. For items that warranted full-text review, NI or EV reviewed each item independently. However, in uncertain cases, a second reviewer (JT) was asked to review them.

5.1.2. Data Extraction and Assessment of Study Quality and Potential for Bias. Data from the included studies were independently extracted by NI and EV. If there was more than one publication for the same study, only the most updated or recent versions of the data were reported in the result. All extracted data and information were audited by an independent auditor.

Important quality features, such as randomization details, sample size and power, intention-to-screen (ITS) analysis, length of follow-up, and funding, for each RCT, were extracted. The quality of observational studies was assessed using a modified Newcastle-Ottawa Scale [83]. The quality of diagnostic studies was assessed using a modified Quality Assessment of Diagnostic Accuracy Studies (QUADAS) tool [84]. The GRADE method for assessing the quality of aggregate evidence was used for each comparison using the GRADEpro Guideline Development Tool $[9,85]$. The working group used the GRADE system for ranking outcomes and scored each outcome from the evidence review on a scale from 1 to 9 . Outcomes with a score from 1 to 3 were considered of limited importance, from 4 to 6 important, and from 7 to 9 critical in the development of recommendations for the CRC screening program. Only outcomes that were considered critical or important were included in the GRADE evidence tables.

5.1.3. Synthesizing the Evidence. When clinically homogenous results from two or more trials were available, a meta-analysis was conducted using review manager software (RevMan 5.3) provided by the Cochrane Collaboration [86]. For all outcomes, the dichotomous model with random effects was used. The number of person-years, rather than the total number of subjects, was used, if available. The number of person-years takes into account the fact that different people in the study may have been followed up for different lengths of time.

In order to have comparable control rates across all gFOBT and FS trials, the control rates for the no screening groups in the gFOBT and FS trials were combined and calculated from the total number of cases across all gFOBT and FS trials over the total number of person-years across all gFOBT and FS trials.

Statistical heterogeneity was calculated using $\chi^{2}$ test for heterogeneity and $I^{2}$ percentage. A probability level for $\chi^{2}$ 
TABLE 1: Description of the quality of evidence grades according to Grading of Recommendations, Assessment, Development and Evaluations (GRADE) [9].

\begin{tabular}{ll}
\hline Grade & Definition \\
\hline High & We are very confident that the true effect lies close to that of the estimate of the effect \\
Moderate & $\begin{array}{l}\text { We are moderately confident in the effect estimate: the true effect is likely to be close to the estimate of the } \\
\text { effect, but there is a possibility that it is substantially different } \\
\text { Our confidence in the effect estimate is limited: the true effect may be substantially different from the estimate } \\
\text { of the effect } \\
\text { Wew }\end{array}$ \\
Very low & estimate of effect
\end{tabular}

statistic less than or equal to $10 \%(p \leq 0.10)$ and/or an $I^{2}$ greater than $50 \%$ was considered indicative of statistical heterogeneity.

5.1.4. Process for Developing Conclusions. The working group members met in person on four occasions to develop evidence-based conclusions through consensus. For each comparison (e.g., gFOBT versus no screening) the working group assessed the quality of the body of evidence for each outcome using the GRADE process [9]. Five factors were assessed for each outcome in each comparison: the risk of bias, inconsistency, indirectness, imprecision, and publication bias. Observational studies were initially graded as low quality and RCTs as high quality; the quality of the evidence was downgraded when serious threats were identified to one or more factors. At the in person meetings, the working group discussed each comparison and agreed on the overall certainty of the evidence across outcomes (Table 1), whether the desirable anticipated effects were large, whether the undesirable anticipated effects were small, and whether the desirable effects were large relative to the undesirable effects. For each comparison, conclusions were developed that reflected these working group discussions.

\section{Results}

6.1. Literature Search Results. A total of 7538 studies were identified and 378 were selected for full-text review. Of those, 48 met the predefined eligibility criteria for this systematic review. An additional 27 articles were found from the reference lists. After our literature search, we became aware of and included an updated publication for one of the FS screening RCTs that had already been identified [21]. A total of 76 articles were included of which eight were systematic reviews $[10,29,30,59,68,87-89], 39$ [6, 11$28,60-66,69-81]$ were from 30 RCTs, 19 were prospective studies [31-43, 52, 53, 55-57, 67], five were retrospective studies [44-48], and five were case-control studies [49-51, 54, 58]. Evidence from five of the eight systematic reviews was included either because the reviews were the most recent systematic review with the highest quality evidence for a particular outcome or because they included an outcome of interest not covered by other high-quality reviews $[10,29,30$, 59, 68]. After the search process and quality assessment, a total of 73 articles were included in this systematic review. The search flow diagram, the characteristics and quality of the included systematic reviews and studies, and the meta-analyses can be found online or in Supplementary Figures 1 to 19 (see Supplementary Material available online at http://dx.doi.org/10.1155/2016/2878149) [8]. Table 2 provides a summary of the number and type of studies used for each comparison.

\section{Interpretation and Conclusions}

The following are the conclusions developed by the working group based on the review of the evidence and meta-analyses. When discussing the effects of various screening tests, the reported outcomes vary by test. There was strong agreement among the members of the working group that CRC-related mortality and complications from screening tests were critical outcomes for recommendation development. All-cause mortality, CRC incidence, participation rate, and diagnostic outcomes were considered important outcomes of interest.

7.1. Fecal Tests for Occult Blood. There was strong evidence to support the use of fecal tests for occult blood to screen people at average risk for CRC.

\subsubsection{Guaiac Fecal Occult Blood Test (gFOBT) versus No Screening}

(i) The overall certainty of the evidence was high, suggesting a definite reduction in CRC-related mortality (Table 3 and Supplementary Figures 1 to 3 ). The magnitude of the effect was small (relative risk [RR], 0.87; $95 \%$ confidence interval [CI], 0.82 to 0.92 ). The magnitude of benefit was comparable to the disease-specific reduction in mortality from mammography for breast cancer screening (RR, 0.79; 95\% CI, 0.68 to 0.90 ) [90] but was less than that from the human papillomavirus (HPV) test for cervical cancer screening (hazard ratio [HR], 0.52; 95\% CI, 0.33 to 0.83 ) [91]. The anticipated harms associated with gFOBT (including follow-up colonoscopy for people with positive tests) are small and outweighed by the benefits.

\subsubsection{Fecal Immunochemical Test (FIT) versus gFOBT}

(i) The overall certainty of the evidence was moderate (Table 4 and Supplementary Figures 7 to 10). The 


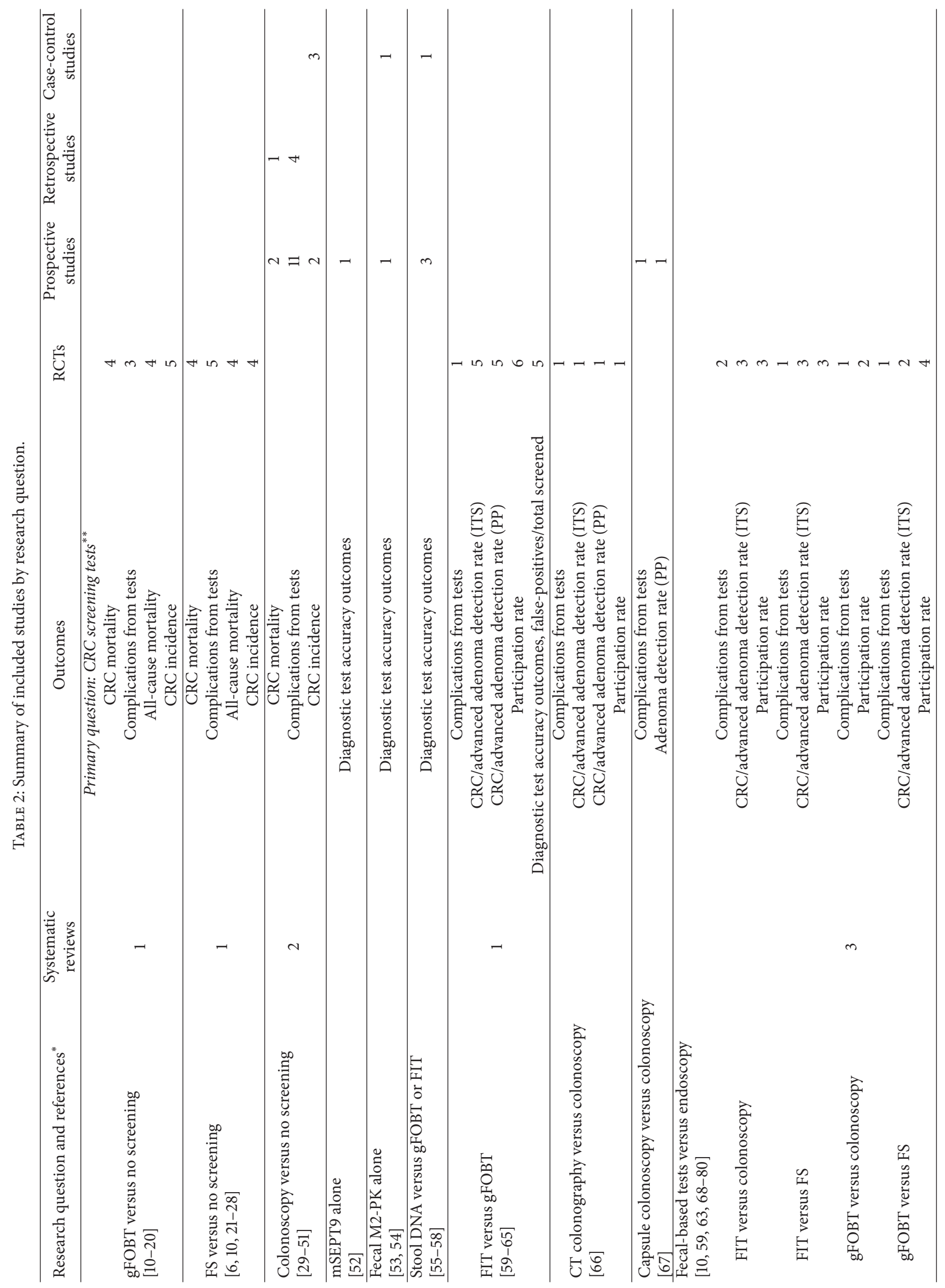




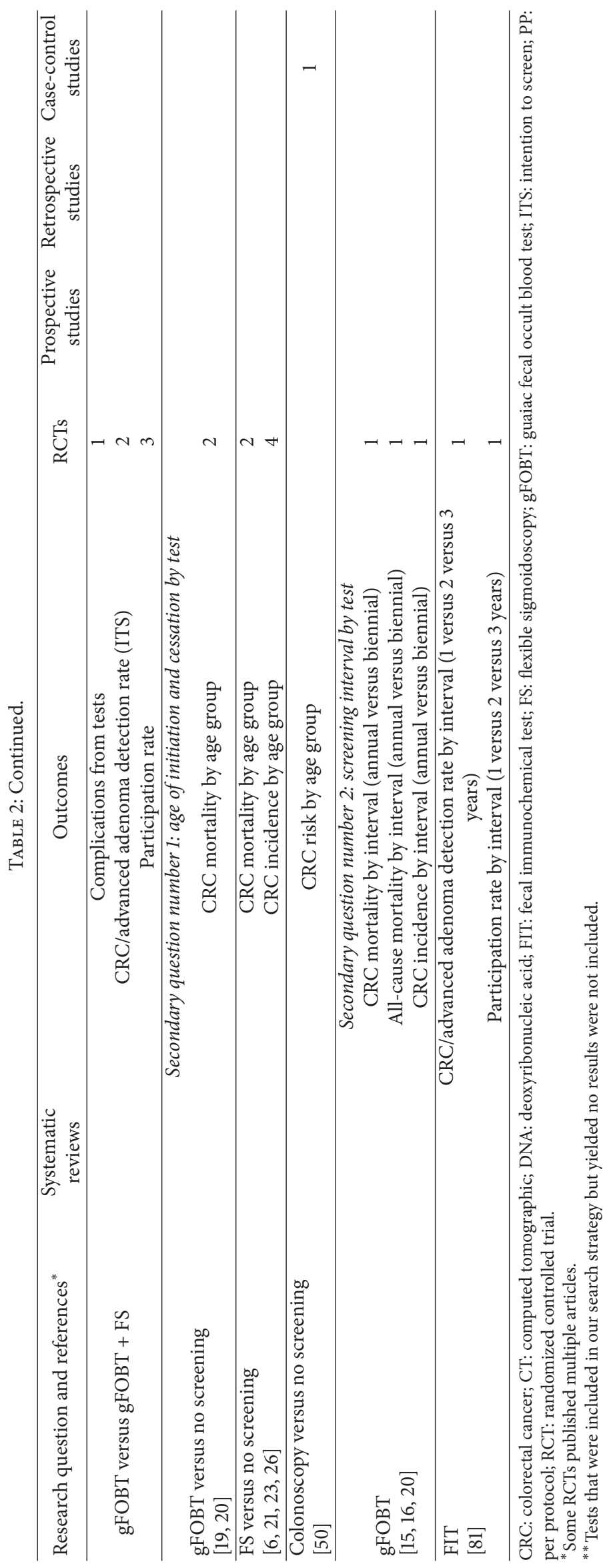




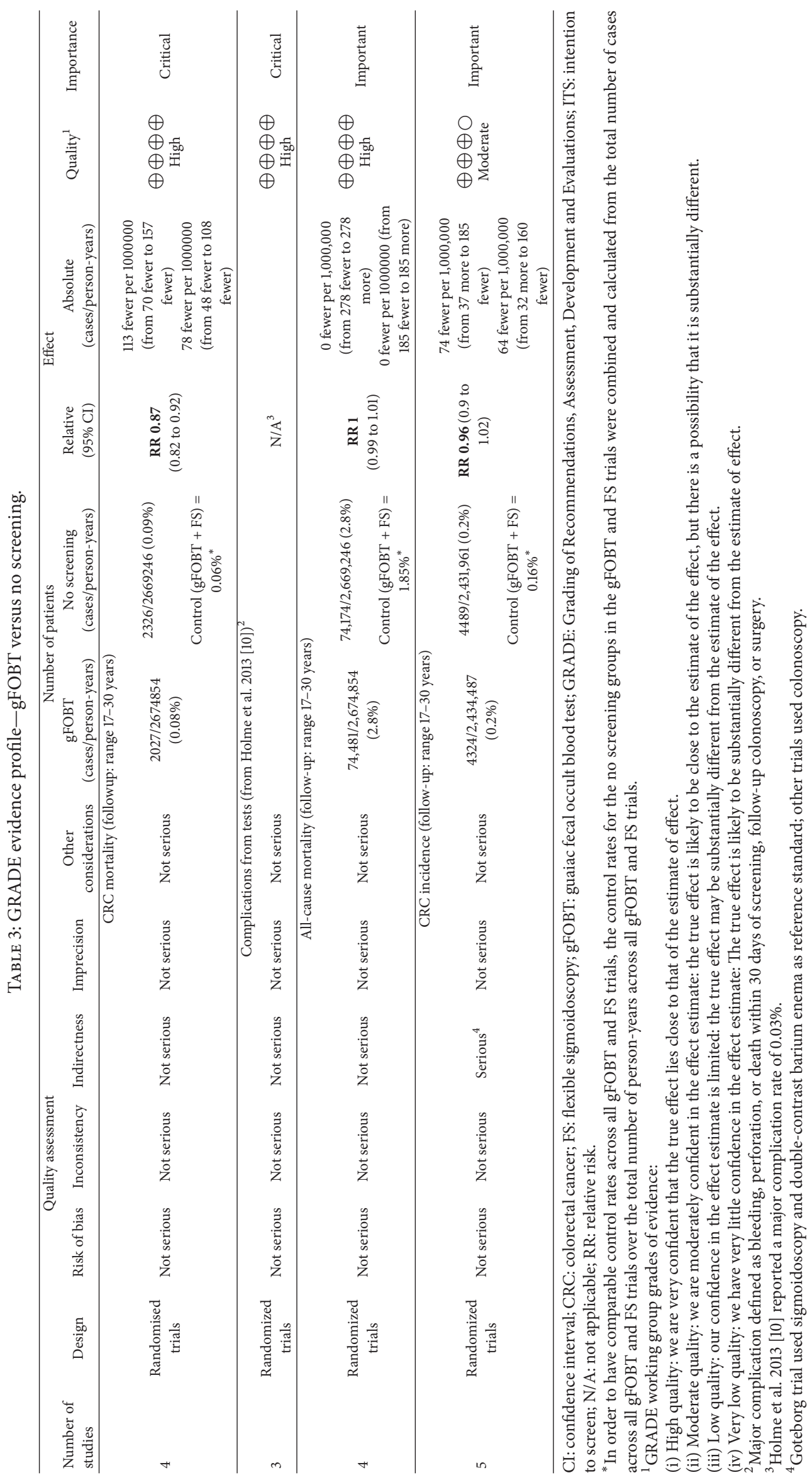




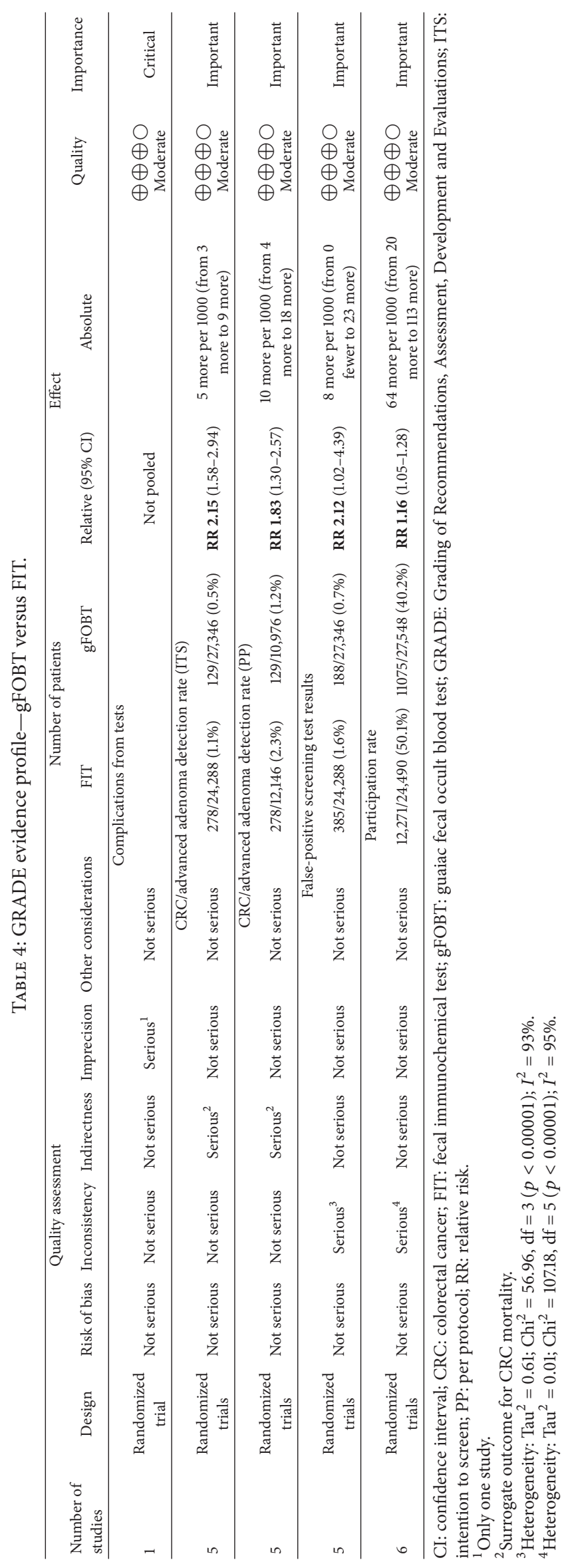


magnitude of the desirable anticipated effects was at least equivalent to gFOBT, and it is likely that the desirable effects of FIT are greater than for gFOBT. The anticipated undesirable effects associated with FIT (including follow-up colonoscopy for people with positive tests) are small and outweighed by the benefits.

(ii) While there were well-designed randomized controlled trials (RCTs) comparing FIT with gFOBT, the outcomes of these trials (participation and detection rates) were considered to be less important than CRCrelated mortality. However, it was anticipated that the reduction in CRC-related mortality and the complications resulting from screening with FIT would be at least equivalent to those observed from screening with gFOBT. FIT's greater sensitivity for detection of CRC and advanced adenomas compared with gFOBT suggests that the reduction in CRC incidence with FIT could be greater than with gFOBT; however, the magnitude and significance of any additional benefit of FIT over gFOBT are unknown. It is important to highlight that the FIT positivity threshold selected would be an important determinant of the magnitude of the benefits and harms of FIT relative to gFOBT.

7.2. Lower Bowel Endoscopy. There was strong evidence to support the use of flexible sigmoidoscopy (FS) to screen people at average risk for CRC. There was no direct evidence to support the use of colonoscopy to screen people at average risk for CRC, but evidence from FS informed the assessment of the benefits and harms of colonoscopy in screening people at average risk for CRC.

\subsubsection{FS versus No Screening}

(i) The overall certainty of the evidence was high, suggesting that FS has a definite effect on CRCrelated mortality and incidence when compared with no screening (Table 5 and Supplementary Figures 4 to 6). The magnitude of the effect on CRC mortality was modest (RR, 0.72 ; 95\% CI, 0.65 to 0.80 ); it exceeds the anticipated disease-specific reduction in mortality from $\mathrm{gFOBT}$ for CRC screening (RR, 0.87; 95\% CI, 0.82 to 0.92 ) and is similar to the effects of mammography on breast cancer mortality (RR, 0.79; 95\% CI, 0.68 to 0.90 ) [90] and of the HPV test on cervical cancer mortality (HR, 0.52 ; 95\% CI, 0.33 to 0.83 ) [91]. The effect on survival with FS was also comparable to the benefit achieved with the current standard of care for patients with completely resected stage III CRC (5-fluorouracil/leucovorin plus oxaliplatin [FOLFOX or FLOX] versus 5-fluorouracil/leucovorin alone, HR for overall survival at six years, $0.80 ; 95 \% \mathrm{CI}, 0.65$ to 0.97 ) [92]. The anticipated harms associated with FS (including follow-up colonoscopy for people with positive tests) were small and outweighed by the benefits.

\subsubsection{Colonoscopy versus No Screening}

(i) The overall certainty of direct evidence supporting the use of colonoscopy to screen people at average risk for CRC was very low when compared with no screening (Table 6). The desirable and undesirable anticipated effects were uncertain.

(ii) It is anticipated that the benefit of screening with colonoscopy would be at least equivalent to that observed for screening with FS; however, the magnitude of additional benefit over FS, if any, is unknown. The magnitude of additional undesirable effects of colonoscopy relative to FS is also unknown.

7.3. Fecal Tests for Occult Blood versus Lower Bowel Endoscopy. There was insufficient evidence to determine how fecal tests for occult blood perform compared with lower bowel endoscopy to screen people at average risk for CRC (Supplementary Tables 1 to 5 and Supplementary Figures 11 to 19).

(i) The studies that compared one-time fecal tests for occult blood to lower bowel endoscopy were heterogeneous, with few comparisons where data could be pooled. However, in general, the evidence suggested that participation was higher and detection rate was lower with fecal-based tests compared with endoscopic tests.

(ii) The overall certainty of the evidence was low. CRCrelated mortality was not evaluated and the design of the studies favoured endoscopic tests because the comparison was to one-time fecal-based testing (rather than repeated testing over time, which is how these tests are used in usual practice). There was significant heterogeneity in participation. The undesirable anticipated effects of endoscopy (including follow-up endoscopy for people with positive fecal tests) are probably small. It is uncertain whether the desirable effects are large relative to the undesirable effects.

\subsection{Radiological Tests}

7.4.1. Computed Tomography Colonography versus Colonoscopy. There was insufficient evidence to determine how computed tomography colonography performs compared with colonoscopy to screen people at average risk for CRC (results not shown; see [8]).

(i) The overall certainty of the evidence was low. The desirable and undesirable anticipated effects were uncertain.

7.4.2. Capsule Colonoscopy versus Colonoscopy. There was insufficient evidence to determine how capsule colonoscopy performs compared with colonoscopy to screen people at average risk for CRC (results not shown; see [8]).

(i) The overall certainty of the evidence was very low. The desirable and undesirable anticipated effects were uncertain. 


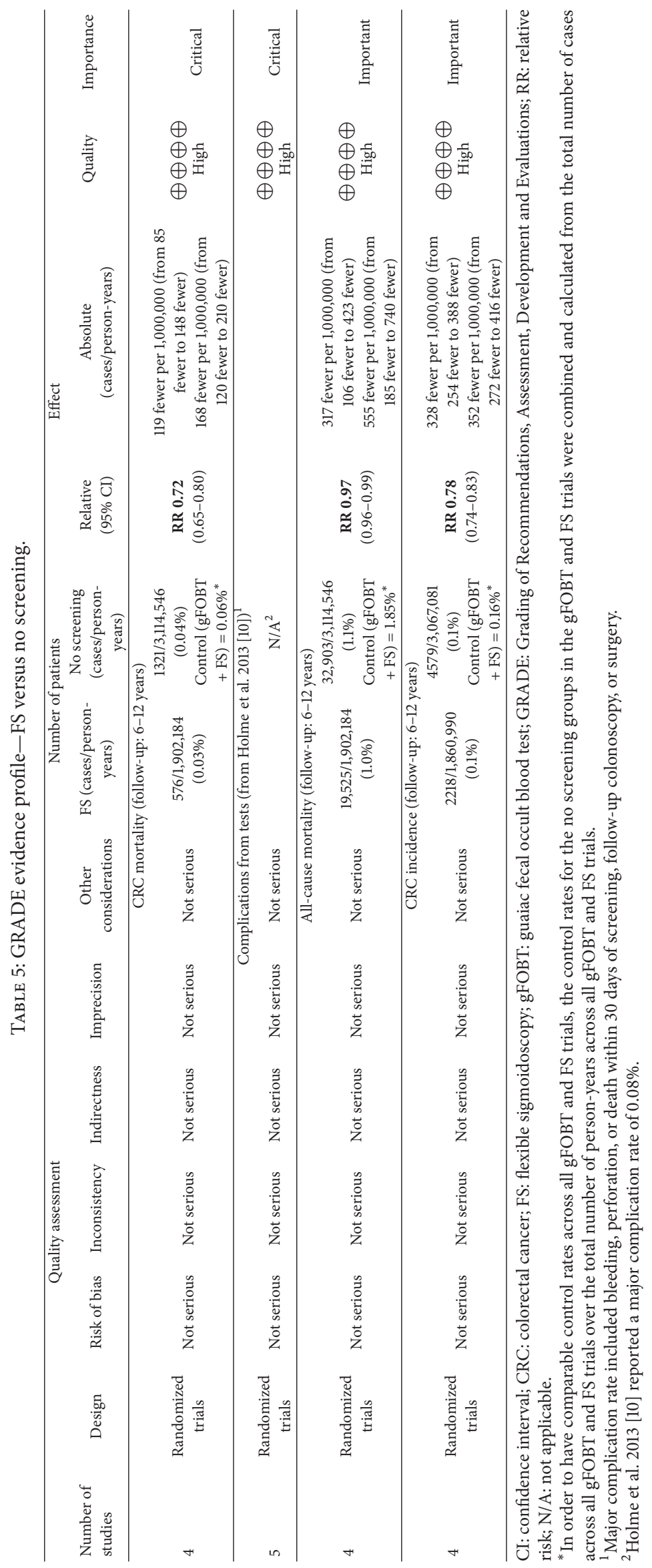




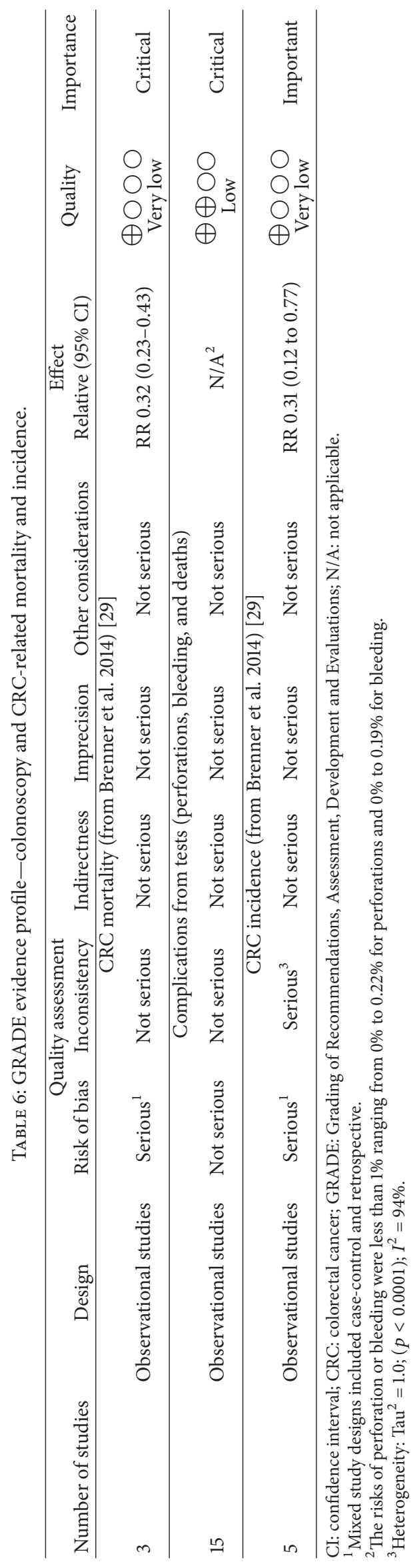


7.4.3. Double-Contrast Barium Enema (DCBE). There was no evidence to support the use of DCBE to screen people at average risk for CRC.

(i) Since 2006, there has been no new published evidence on this topic. Most recent CRC guidelines except for a 2008 guideline by the American Cancer Society, the US Multi-Society Task Force on Colorectal Cancer, and the American College of Radiology [93] have not endorsed the use of DCBE for screening [94-98].

\subsection{DNA Tests}

7.5.1. Stool DNA versus Fecal Occult Blood Tests (gFOBT or FIT). There was insufficient evidence to determine how stool DNA performs compared with gFOBT or FIT to screen people at average risk for CRC (results not shown; see [8]).

(i) The overall certainty of the evidence was very low. The desirable and undesirable anticipated effects were uncertain.

7.5.2. Other DNA Tests. There was insufficient evidence to support the use of mSEPT9 to screen people at average risk for CRC (results not shown; see [8]).

(i) The overall certainty of the evidence was very low. The desirable and undesirable anticipated effects were uncertain.

\subsection{Metabolomic Tests}

7.6.1. Fecal M2-PK. There was insufficient evidence to support the use of fecal M2-PK to screen people at average risk for CRC (results not shown; see [8]).

(i) The overall certainty of the evidence was very low. The desirable and undesirable anticipated effects were uncertain.

7.6.2. Other Metabolomic Tests. There was no evidence to support the use of other metabolomic tests (e.g., low levels of hydroxylated polyunsaturated long chain fatty acids [Cologic]) to screen people at average risk for CRC.

\subsection{Age of Initiation/Cessation}

7.7.1. Age of Initiation/Cessation with gFOBT. Currently, the Ontario CRC screening program recommends that average risk individuals initiate screening with gFOBT beginning at 50 years of age and ending at age 74 . There was insufficient evidence to support changing the ages of initiation and cessation for CRC screening with gFOBT in Ontario (results not shown; see [8]).

(i) The overall certainty of the evidence was very low. There was insufficient evidence to demonstrate differences in reduction of CRC mortality using gFOBT across age groups. The desirable and undesirable anticipated effects across age groups were uncertain.
7.7.2. Age of Initiation/Cessation with FS. There was insufficient evidence to recommend ages of initiation or cessation when screening with FS in people at average risk for CRC (results not shown; see [8]).

(i) The overall certainty of the evidence was very low. There was insufficient evidence to demonstrate differences in reduction of CRC mortality or incidence using FS across age groups. The desirable and undesirable anticipated effects across age groups were uncertain.

(ii) Of the four large FS RCTs, three examined "once in a lifetime" FS between the ages of 55 and 64, while the fourth RCT examined baseline FS between the ages of 55 and 74 with a second FS after three or five years.

7.7.3. Age of Initiation/Cessation with Colonoscopy. There was insufficient evidence to recommend an age of initiation or cessation to screen with colonoscopy in people at average risk for CRC (results not shown; see [8]).

(i) The overall certainty of the evidence was very low. There was insufficient evidence to demonstrate differences in CRC detection using colonoscopy across age groups. The desirable and undesirable anticipated effects across age groups were uncertain.

(ii) Currently, the Ontario CRC screening program does not recommend colonoscopy to screen persons at average risk for CRC. The program does recommend colonoscopy in people at increased risk (one or more first-degree relatives with CRC) starting at 50 years of age or 10 years younger than the age at which the relative was diagnosed, whichever occurred first.

7.7.4. Age of Initiation/Cessation with FIT. There were no studies that met our inclusion criteria for age of initiation/cessation for FIT.

\subsection{Screening Intervals}

7.8.1. gFOBT Intervals. There was evidence to suggest that either annual or biennial screening using gFOBT in people at average risk for CRC reduces CRC-related mortality (results not shown; see [8]).

(i) The overall certainty of the evidence was moderate. The desirable anticipated effects on CRC mortality were small and similar for annual or biennial screening. The undesirable anticipated effects were not reported for each interval group. Anticipated harms associated with gFOBT (including follow-up colonoscopy for people with positive tests) were small for biennial screening and were likely to be greater for annual screening. In addition, annual screening is anticipated to increase burden to the participant.

7.8.2. FIT Intervals. There was insufficient evidence to recommend an interval to screen people at average risk for CRC using FIT (results not shown; see [8]). 
TABLE 7: Responses of the expert panel to the working group's conclusions.

\begin{tabular}{|c|c|c|c|c|c|}
\hline \multirow[b]{2}{*}{ Conclusions } & \multicolumn{4}{|c|}{ Reviewer ratings $(N=27)$} & \multirow[b]{2}{*}{$\begin{array}{c}\text { Strongly agrec } \\
(\%)\end{array}$} \\
\hline & $\begin{array}{c}\text { Strongly } \\
\text { disagree }(\%)\end{array}$ & Disagree (\%) & $\begin{array}{c}\text { Neither agree } \\
\text { nor disagree }(\%)\end{array}$ & Agree (\%) & \\
\hline $\begin{array}{l}\text { (1) Strong evidence to support use of fecal tests } \\
\text { for occult blood to screen people at average risk } \\
\text { for CRC }\end{array}$ & 0 & 0 & $1(4)$ & $10(37)$ & $16(59)$ \\
\hline $\begin{array}{l}\text { (2) Strong evidence to support the use of FS to } \\
\text { screen people at average risk for CRC }\end{array}$ & 0 & 0 & 0 & $7(26)$ & $20(74)$ \\
\hline $\begin{array}{l}\text { (3) No direct evidence to support the use of } \\
\text { colonoscopy to screen people at average risk for } \\
\text { CRC, but evidence from FS informs the } \\
\text { assessment of benefits and harms of colonoscopy } \\
\text { to screen people at average risk for CRC }\end{array}$ & 0 & $2(8)$ & $2(8)$ & $14(54)$ & $8(31)$ \\
\hline $\begin{array}{l}\text { (4) Insufficient evidence to determine how fecal } \\
\text { tests for occult blood perform compared with } \\
\text { lower bowel endoscopy to screen people at } \\
\text { average risk for CRC }\end{array}$ & 0 & $2(8)$ & $4(15)$ & $13(50)$ & $7(27)$ \\
\hline $\begin{array}{l}\text { (5) Insufficient evidence to determine how CT } \\
\text { colonography performs compared with } \\
\text { colonoscopy to screen people at average risk for } \\
\text { CRC }\end{array}$ & 0 & 0 & $1(4)$ & $8(33)$ & $15(63)$ \\
\hline $\begin{array}{l}\text { (6) Insufficient evidence to determine how capsule } \\
\text { endoscopy performs compared with colonoscopy } \\
\text { to screen people at average risk for CRC }\end{array}$ & 0 & 0 & 0 & $1(4)$ & $23(96)$ \\
\hline $\begin{array}{l}\text { (7) No evidence to support the use of } \\
\text { double-contrast barium enema to screen people at } \\
\text { average risk for CRC }\end{array}$ & 0 & 0 & $2(8)$ & 0 & $23(92)$ \\
\hline $\begin{array}{l}\text { (8) Insufficient evidence to determine how fecal } \\
\text { DNA performs compared with guaiac fecal occult } \\
\text { blood test (gFOBT) or fecal immunochemical test } \\
\text { (FIT) to screen people at average risk for CRC }\end{array}$ & 0 & 0 & 0 & $8(33)$ & $16(67)$ \\
\hline $\begin{array}{l}\text { (9) Insufficient evidence to support the use of } \\
\text { mSEPT9 to screen people at average risk for CRC }\end{array}$ & 0 & 0 & 0 & $2(8)$ & $23(92)$ \\
\hline $\begin{array}{l}\text { (10) Insufficient evidence to support the use of } \\
\text { fecal M2-PK to screen people at average risk for } \\
\text { CRC }\end{array}$ & 0 & 0 & 0 & $3(12)$ & $23(89)$ \\
\hline $\begin{array}{l}\text { (11) Insufficient evidence to support the use of } \\
\text { other metabolomic tests to screen people at } \\
\text { average risk for CRC }\end{array}$ & 0 & 0 & $1(4)$ & $2(9)$ & $20(87)$ \\
\hline $\begin{array}{l}\text { (12) Insufficient evidence to support changing } \\
\text { ages of initiation and cessation for CRC screening } \\
\text { with gFOBT in Ontario }\end{array}$ & 0 & $1(4)$ & $1(4)$ & $9(36)$ & $14(56)$ \\
\hline $\begin{array}{l}\text { (13) Insufficient evidence to recommend an age of } \\
\text { initiation or cessation to screen with FS in people } \\
\text { at average risk for CRC }\end{array}$ & 0 & 0 & $3(12)$ & $9(36)$ & $13(52)$ \\
\hline $\begin{array}{l}\text { (14) Insufficient evidence to recommend an age of } \\
\text { initiation or cessation to screen with colonoscopy } \\
\text { in people at average risk for CRC }\end{array}$ & 0 & 0 & $4(16)$ & $10(40)$ & $11(44)$ \\
\hline $\begin{array}{l}\text { (15) Evidence suggests annual or biennial } \\
\text { screening using gFOBT in people at average risk } \\
\text { for CRC reduces CRC mortality }\end{array}$ & 0 & 0 & $1(4)$ & $11(42)$ & $14(54)$ \\
\hline $\begin{array}{l}\text { (16) Insufficient evidence to recommend an } \\
\text { interval to screen people at average risk for CRC } \\
\text { using FIT }\end{array}$ & 0 & $1(4)$ & $4(15)$ & $13(50)$ & $8(31)$ \\
\hline
\end{tabular}


(i) The overall certainty of the evidence was very low. The desirable and undesirable anticipated effects were uncertain.

7.8.3. FS and Colonoscopy Intervals. There were no studies that met our inclusion criteria for screening intervals for FS or colonoscopy.

\section{Summary and Next Steps}

This evidentiary base summarizes the known clinical effectiveness and safety of CRC screening tests. Concurrently, the Canadian Task Force on Preventive Health Care (CTFPH) [99] and the US Preventive Services Task Force (USPSTF) have published guidelines on CRC screening [100]. The audience for the 3 reviews differed slightly: the current review seeks to provide guidance to the CRC screening program in light of emerging evidence in CRC screening while the CTFPH and the USPSTF specify "primary care physicians" and "primary care clinicians and patients" as their target audiences, respectively. All 3 reviews support the use of fecal testing (gFOBT or FIT) and flexible sigmoidoscopy but treat colonoscopy slightly differently. The CTFPH recommends against colonoscopy while the USPSTF endorses it as one of a range of options. In the current review, we grade the evidence only (recommendations for Ontario's CRC screening program are released separately; see below). Our interpretation of the evidence acknowledges that the strong evidence in favour of flexible sigmoidoscopy does inform the assessment of colonoscopy. However, this evidence is both indirect and incomplete (magnitude of additional benefit from colonoscopy and of additional harms is unknown). In order to have complete understanding of the benefits and harms of colonoscopy, we await the results of ongoing randomized controlled trials in colonoscopy for average risk screening, anticipated in the 2020s.

The evidence from the current review is central to the ongoing development of Ontario's CRC screening program. However, this evidentiary base is necessary but not sufficient to guide program development as other context-specific criteria such as cost-effectiveness, existing program design, and public acceptability and feasibility (from an organizational and economic perspective) must be considered. In addition, the program must also consider the balance between choice and informed decision making and issues not well addressed by the evidence such as how to best implement CRC screening when there is more than one CRC screening test supported by high-quality evidence. An expert panel comprising members from national and international screening programs, primary care physicians, general surgeons, gastroenterologists, pathologists and laboratory medicine professionals, nurse endoscopists, and members of the public was convened to provide guidance on how to incorporate this evidence in light of the other issues listed above. Their level of agreement with the conclusions is reflected in Table 7. The CCC program will use findings from the evidence summary as well as expert panel recommendations to guide its ongoing development. The specific recommendations resulting from this process have been released recently and can be accessed online at https://www.cancercare.on.ca/common/pages/UserFile.aspx?fileId=358486.

\section{Competing Interests}

Jill Tinmouth was a lead scientist at Cancer Care Ontario for ColonCancerCheck and paid as a consultant for this work. Catherine Dubé published an editorial in Can J. Gastro 201226 417-18 [101]. Michael Gould has an endoscopy clinic in Toronto, is a consultant for Abbott Laboratories, is on the Board of Directors for the Ontario Association of Gastroenterology and the Canadian Digestive Health Foundation, and is the Clinical Lead for ColonCancerCheck. For the remaining authors none were declared. The Program in Evidence-based Care (PEBC) is a provincial initiative of Cancer Care Ontario supported by the Ontario Ministry of Health and Long-Term Care. All work produced by the PEBC is editorially independent from the Ontario Ministry of Health and Long-Term Care.

\section{Acknowledgments}

The authors would like to thank the following individuals for their assistance in developing this report: (i) Melissa Brouwers, Meghan Hatcher, Sheila McNair, and Hans Messersmith for providing feedback on draft versions, (ii) Waseem Hijazi for conducting a data audit, and (iii) Sara Miller and Jenny Lass for copyediting.

\section{References}

[1] Colorectal Cancer Association of Canada, 2016, http://www .colorectal-cancer.ca/en/just-the-facts/colorectal/.

[2] World Cancer Research Fund International website, 2016, http:// www.wcrf.org/int/cancer-facts-figures/data-specific-cancers/ colorectal-cancer-statistics.

[3] H. Brenner, J. Chang-Claude, C. M. Seiler, and M. Hoffmeister, "Interval cancers after negative colonoscopy: population-based case-control study," Gut, vol. 61, no. 11, pp. 1576-1582, 2012.

[4] O. Kronborg, C. Fenger, J. Olsen, O. D. Jørgensen, and O. Søndergaard, "Randomised study of screening for colorectal cancer with faecal-occult-blood test," The Lancet, vol. 348, no. 9040, pp. 1467-1471, 1996.

[5] E. J. A. Morris, L. E. Whitehouse, T. Farrell et al., "A retrospective observational study examining the characteristics and outcomes of tumours diagnosed within and without of the English NHS Bowel Cancer Screening Programme," British Journal of Cancer, vol. 107, no. 5, pp. 757-764, 2012.

[6] N. Segnan, P. Armaroli, L. Bonelli et al., "Once-only sigmoidoscopy in colorectal cancer screening: Follow-up findings of the italian randomized controlled trial - SCORE," Journal of the National Cancer Institute, vol. 103, no. 17, pp. 1310-1322, 2011.

[7] Canadian Quality Cancer of Ontario, 2016, http://www.csqi.on .ca/by_patient_journey/screening/colorectal_screening_participation.

[8] J. Tinmouth, E. Vella, NN. Baxter et al., "Colorectal cancer screening in average risk populations: evidence summary," Program in Evidence-Based Care Evidence Summary 15-14, CCO, Toronto, Canada, 2015, https://www.cancercare.on.ca/ toolbox/qualityguidelines/clin-program/screening-ebs/. 
[9] G. Guyatt, A. D. Oxman, E. A. Akl et al., "GRADE guidelines: 1. Introduction-GRADE evidence profiles and summary of findings tables," Journal of Clinical Epidemiology, vol. 64, no. 4, pp. 383-394, 2011.

[10] Ø. Holme, M. Bretthauer, A. Fretheim, J. Odgaard-Jensen, and G. Hoff, "Flexible sigmoidoscopy versus faecal occult blood testing for colorectal cancer screening in asymptomatic individuals," Cochrane Database of Systematic Reviews, vol. 9, Article ID CD009259, 2013.

[11] J. Kewenter and H. Brevinge, "Endoscopic and surgical complications of work-up in screening for colorectal cancer," Diseases of the Colon and Rectum, vol. 39, no. 6, pp. 676-680, 1996.

[12] O. Kronborg, O. D. Jørgensen, C. Fenger, and M. Rasmussen, "Randomized study of biennial screening with a faecal occult blood test: results after nine screening rounds," Scandinavian Journal of Gastroenterology, vol. 39, no. 9, pp. 846-851, 2004.

[13] E. Lindholm, H. Brevinge, and E. Haglind, "Survival benefit in a randomized clinical trial of faecal occult blood screening for colorectal cancer," British Journal of Surgery, vol. 95, no. 8, pp. 1029-1036, 2008.

[14] J. S. Mandel, J. H. Bond, T. R. Church et al., "Reducing mortality from colorectal cancer by screening for fecal occult blood. Minnesota Colon Cancer Control Study," The New England Journal of Medicine, vol. 328, no. 19, pp. 1365-1371, 1993.

[15] J. S. Mandel, T. R. Church, J. H. Bond et al., "The effect of fecal occult-blood screening on the incidence of colorectal cancer," The New England Journal of Medicine, vol. 343, no. 22, pp. 16031607, 2000.

[16] J. S. Mandel, T. R. Church, F. Ederer, and J. H. Bond, "Colorectal cancer mortality: effectiveness of biennial screening for fecal occult blood," Journal of the National Cancer Institute, vol. 91, no. 5, pp. 434-437, 1999.

[17] H. Paimela, N. Malila, T. Palva, T. Hakulinen, H. Vertio, and H. Järvinen, "Early detection of colorectal cancer with faecal occult blood test screening," British Journal of Surgery, vol. 97, no. 10, pp. 1567-1571, 2010.

[18] M. H. E. Robinson, J. D. Hardcastle, S. M. Moss et al., "The risks of screening: data from the Nottingham randomised controlled trial of faecal occult blood screening for colorectal cancer," Gut, vol. 45 , no. 4 , pp. 588-592, 1999.

[19] J. H. Scholefield, S. M. Moss, C. M. Mangham, D. K. Whynes, and J. D. Hardcastle, "Nottingham trial of faecal occult blood testing for colorectal cancer: a 20-year follow-up," Gut, vol. 61, no. 7, pp. 1036-1040, 2012.

[20] A. Shaukat, S. J. Mongin, M. S. Geisser et al., "Long-term mortality after screening for colorectal cancer," The New England Journal of Medicine, vol. 369, no. 12, pp. 1106-1114, 2013.

[21] Ø. Holme, M. Løberg, M. Kalager et al., "Effect of flexible sigmoidoscopy screening on colorectal cancer incidence and mortality: a randomized clinical trial," The Journal of the American Medical Association, vol. 312, no. 6, pp. 606-615, 2014.

[22] W. S. Atkin, C. F. Cook, J. Cuzick et al., "Single flexible sigmoidoscopy screening to prevent colorectal cancer: baseline findings of a UK multicentre randomised trial," The Lancet, vol. 359, no. 9314, pp. 1291-300, 2002.

[23] W. S. Atkin, R. Edwards, I. Kralj-Hans et al., "Once-only flexible sigmoidoscopy screening in prevention of colorectal cancer: a multicentre randomised controlled trial," The Lancet, vol. 375, no. 9726, pp. 1624-1633, 2010.

[24] G. Hoff, J. Sauar, M. H. Vatn et al., "Polypectomy of adenomas in the prevention of colorectal cancer: 10 years' follow-up of the
Telemark Polyp Study I. A prospective, controlled population study," Scandinavian Journal of Gastroenterology, vol. 31, no. 10, pp. 1006-1010, 1996.

[25] G. Hoff, T. Grotmol, E. Skovlund, and M. Bretthauer, "Risk of colorectal cancer seven years after flexible sigmoidoscopy screening: randomised controlled trial," British Medical Journal, vol. 338, Article ID b1846, 2009.

[26] R. E. Schoen, P. F. Pinsky, J. L. Weissfeld et al., "Colorectalcancer incidence and mortality with screening flexible sigmoidoscopy," The New England Journal of Medicine, vol. 366, no. 25, pp. 2345-2357, 2012.

[27] N. Segnan, C. Senore, B. Andreoni et al., "Baseline findings of the Italian multicenter randomized controlled trial of 'onceonly sigmoidoscopy'-SCORE," Journal of the National Cancer Institute, vol. 94, no. 23, pp. 1763-1772, 2002.

[28] E. Thiis-Evensen, G. S. Hoff, J. Sauar, F. Langmark, B. M. Majak, and M. H. Vatn, "Population-based surveillance by colonoscopy: effect on the incidence of colorectal cancer: Telemark Polyp Study I," Scandinavian Journal of Gastroenterology, vol. 34, no. 4, pp. 414-420, 1999.

[29] H. Brenner, C. Stock, and M. Hoffmeister, "Effect of screening sigmoidoscopy and screening colonoscopy on colorectal cancer incidence and mortality: systematic review and meta-analysis of randomised controlled trials and observational studies," British Medical Journal, vol. 348, article g2467, 2014.

[30] Y. Niv, R. Hazazi, Z. Levi, and G. Fraser, "Screening colonoscopy for colorectal cancer in asymptomatic people: a meta-analysis," Digestive Diseases and Sciences, vol. 53, no. 12, pp. 3049-3054, 2008.

[31] H.-M. Chiu, H.-P. Wang, Y.-C. Lee et al., "A prospective study of the frequency and the topographical distribution of colon neoplasia in asymptomatic average-risk Chinese adults as determined by colonoscopic screening," Gastrointestinal Endoscopy, vol. 61, no. 4, pp. 547-553, 2005.

[32] J. A. DiSario, P. G. Foutch, H. D. Mai, K. Pardy, and R. K. Manne, "Prevalence and malignant potential of colorectal polyps in asymptomatic, average-risk men," The American Journal of Gastroenterology, vol. 86, no. 8, pp. 941-945, 1991.

[33] T. F. Imperiale, D. R. Wagner, C. Y. Lin, G. N. Larkin, J. D. Rogge, and D. F. Ransohoff, "Risk of advanced proximal neoplasms in asymptomatic adults according to the distal colorectal findings," The New England Journal of Medicine, vol. 343, no. 3, pp. 169$174,2000$.

[34] D. A. Johnson, M. S. Gurney, R. J. Volpe et al., "A prospective study of the prevalence of colonic neoplasms in asymptomatic patients with an age-related risk," The American Journal of Gastroenterology, vol. 85, no. 8, pp. 969-974, 1990.

[35] C. J. Kahi, T. F. Imperiale, B. E. Juliar, and D. K. Rex, "Effect of screening colonoscopy on colorectal cancer incidence and mortality," Clinical Gastroenterology and Hepatology, vol. 7, no. 7, pp. 770-775, 2009.

[36] D. H. Kim, S. Y. Lee, K. S. Choi et al., "The usefulness of colonoscopy as a screening test for detecting colorectal polyps," Hepatogastroenterology, vol. 54, no. 80, pp. 2240-2242, 2007.

[37] D. H. Kim, P. J. Pickhardt, A. J. Taylor et al., "CT colonography versus colonoscopy for the detection of advanced neoplasia," The New England Journal of Medicine, vol. 357, no. 14, pp. 14031412, 2007.

[38] D. A. Lieberman, D. G. Weiss, J. H. Bond, D. J. Ahnen, H. Garewal, and G. Chejfec, "Use of colonoscopy to screen asymptomatic adults for colorectal cancer. Veterans Affairs 
Cooperative Study Group 380," The New England Journal of Medicine, vol. 343, no. 3, pp. 162-168, 2000.

[39] C. N. Manser, L. M. Bachmann, J. Brunner, F. Hunold, P. Bauerfeind, and U. A. Marbet, "Colonoscopy screening markedly reduces the occurrence of colon carcinomas and carcinomarelated death: a closed cohort study," Gastrointestinal Endoscopy, vol. 76, no. 1, pp. 110-117, 2012.

[40] J. Regula, M. Rupinski, E. Kraszewska et al., "Colonoscopy in colorectal-cancer screening for detection of advanced neoplasia," The New England Journal of Medicine, vol. 355, no. 18, pp. 1863-1872, 2006.

[41] J. D. Rogge, M. F. Elmore, S. J. Mahoney et al., "Low-cost, office-based, screening colonoscopy," The American Journal of Gastroenterology, vol. 89, no. 10, pp. 1775-1780, 1994.

[42] P. Schoenfeld, B. Cash, A. Flood et al., "Colonoscopic screening of average-risk women for colorectal neoplasia," The New England Journal of Medicine, vol. 352, no. 20, pp. 2061-2068, 2005.

[43] M.-S. Soon, R. A. Kozarek, K. Ayub, A. Soon, T.-Y. Lin, and O. S. Lin, "Screening colonoscopy in Chinese and Western patients: a comparative study," The American Journal of Gastroenterology, vol. 100, no. 12, pp. 2749-2755, 2005.

[44] J. W. Choe, H.-S. Chang, S.-K. Yang et al., "Screening colonoscopy in asymptomatic average-risk Koreans: analysis in relation to age and sex," Journal of Gastroenterology and Hepatology, vol. 22, no. 7, pp. 1003-1008, 2007.

[45] S. J. Chung, Y. S. Kim, S. Y. Yang et al., "Prevalence and risk of colorectal adenoma in asymptomatic Koreans aged $40-49$ years undergoing screening colonoscopy," Journal of Gastroenterology and Hepatology, vol. 25, no. 3, pp. 519-525, 2010.

[46] R. Nishihara, K. Wu, P. Lochhead et al., "Long-term colorectalcancer incidence and mortality after lower endoscopy," The New England Journal of Medicine, vol. 369, no. 12, pp. 1095-1105, 2013.

[47] D. N. Prajapati, K. Saeian, D. G. Binion et al., "Volume and yield of screening colonoscopy at a tertiary medical center after change in medicare reimbursement," The American Journal of Gastroenterology, vol. 98, no. 1, pp. 194-199, 2003.

[48] H. Strul, R. Kariv, M. Leshno et al., "The prevalence rate and anatomic location of colorectal adenoma and cancer detected by colonoscopy in average-risk individuals aged 40-80 years," American Journal of Gastroenterology, vol. 101, no. 2, pp. 255$262,2006$.

[49] H. Brenner, J. Chang-Claude, L. Jansen, P. Knebel, C. Stock, and M. Hoffmeister, "Reduced risk of colorectal cancer up to 10 years after screening, surveillance, or diagnostic colonoscopy," Gastroenterology, vol. 146, no. 3, pp. 709-717, 2014.

[50] M. Cotterchio, M. Manno, N. Klar, J. McLaughlin, and S. Gallinger, "Colorectal screening is associated with reduced colorectal cancer risk: a case-control study within the populationbased Ontario Familial Colorectal Cancer Registry," Cancer Causes and Control, vol. 16, no. 7, pp. 865-875, 2005.

[51] C. A. Doubeni, S. Weinmann, K. Adams et al., "Screening colonoscopy and risk for incident late-stage colorectal cancer diagnosis in average-risk adults: a nested case-control study," Annals of Internal Medicine, vol. 5, part 1, pp. 312-320, 2013.

[52] T. R. Church, M. Wandell, C. Lofton-Day et al., "Prospective evaluation of methylated SEPT9 in plasma for detection of asymptomatic colorectal cancer," Gut, vol. 63, no. 2, pp. 317-325, 2014.

[53] U. Haug, S. Hundt, and H. Brenner, "Sensitivity and specificity of faecal tumour M2 pyruvate kinase for detection of colorectal adenomas in a large screening study," British Journal of Cancer, vol. 99, no. 1, pp. 133-135, 2008.

[54] C. Tonus, G. Neupert, and M. Sellinger, "Colorectal cancer screening by non-invasive metabolic biomarker fecal tumor M2-PK," World Journal of Gastroenterology, vol. 12, no. 43, pp. 7007-7011, 2006.

[55] D. A. Ahlquist, D. J. Sargent, C. L. Loprinzi et al., "Stool DNA and occult blood testing for screen detection of colorectal neoplasia," Annals of Internal Medicine, vol. 149, no. 7, pp. 441450, 2008.

[56] T. F. Imperiale, D. F. Ransohoff, S. H. Itzkowitz et al., "Multitarget stool DNA testing for colorectal-cancer screening," The New England Journal of Medicine, vol. 370, no. 14, pp. 1287-1297, 2014.

[57] T. F. Imperiale, D. F. Ransohoff, S. H. Itzkowitz, B. A. Turnbull, and M. E. Ross, "Fecal DNA versus fecal occult blood for colorectal-cancer screening in an average-risk population," The New England Journal of Medicine, vol. 351, no. 26, pp. 2704-2714, 2004.

[58] Y. Koga, N. Yamazaki, S. Takizawa et al., "Gene expression analysis using a highly sensitive DNA microarray for colorectal cancer screening," Anticancer Research, vol. 34, no. 1, pp. 169176, 2014.

[59] C. Hassan, P. Giorgi Rossi, L. Camilloni et al., "Meta-analysis: adherence to colorectal cancer screening and the detection rate for advanced neoplasia, according to the type of screening test," Alimentary Pharmacology and Therapeutics, vol. 36, no. 10, pp. 929-940, 2012.

[60] J. Chubak, A. Bogart, S. Fuller, S. S. Laing, and B. B. Green, "Uptake and positive predictive value of fecal occult blood tests: a randomized controlled trial," Preventive Medicine, vol. 57, no. 5, pp. 671-678, 2013.

[61] A. Federici, P. G. Rossi, P. Borgia, F. Bartolozzi, S. Farchi, and G. Gausticchi, "The immunochemical faecal occult blood test leads to higher compliance than the guaiac for colorectal cancer screening programmes: a cluster randomized controlled trial," Journal of Medical Screening, vol. 12, no. 2, pp. 83-88, 2005.

[62] R. M. Hoffman, S. Steel, E. F. T. Yee, L. Massie, R. M. Schrader, and G. H. Murata, "Colorectal cancer screening adherence is higher with fecal immunochemical tests than guaiac-based fecal occult blood tests: a randomized, controlled trial," Preventive Medicine, vol. 50, no. 5-6, pp. 297-299, 2010.

[63] L. Hol, M. E. Van Leerdam, M. Van Ballegooijen et al., "Screening for colorectal cancer: randomised trial comparing guaiac-based and immunochemical faecal occult blood testing and flexible sigmoidoscopy," Gut, vol. 59, no. 1, pp. 62-68, 2010.

[64] Z. Levi, S. Birkenfeld, A. Vilkin et al., "A higher detection rate for colorectal cancer and advanced adenomatous polyp for screening with immunochemical fecal occult blood test than guaiac fecal occult blood test, despite lower compliance rate. A prospective, controlled, feasibility study," International Journal of Cancer, vol. 128, no. 10, pp. 2415-2424, 2011.

[65] L. G. van Rossum, A. F. van Rijn, R. J. Laheij et al., "Random comparison of guaiac and immunochemical fecal occult blood tests for colorectal cancer in a screening population," Gastroenterology, vol. 135, no. 1, pp. 82-90, 2008.

[66] E. M. Stoop, M. C. de Haan, T. R. de Wijkerslooth et al., "Participation and yield of colonoscopy versus non-cathartic CT colonography in population-based screening for colorectal cancer: a randomised controlled trial," The Lancet Oncology, vol. 13, no. 1, pp. 55-64, 2012. 
[67] S. Groth, H. Krause, R. Behrendt et al., "Capsule colonoscopy increases uptake of colorectal cancer screening," BMC Gastroenterology, vol. 12, article 80, 2012.

[68] C. Littlejohn, S. Hilton, G. J. MacFarlane, and P. Phull, "Systematic review and meta-analysis of the evidence for flexible sigmoidoscopy as a screening method for the prevention of colorectal cancer," British Journal of Surgery, vol. 99, no. 11, pp. 1488-1500, 2012.

[69] D. P. Berry, P. Clarke, J. D. Hardcastle, and K. D. Vellacott, "Randomized trial of the addition of flexible sigmoidoscopy to faecal occult blood testing for colorectal neoplasia population screening," British Journal of Surgery, vol. 84, no. 9, pp. 12741276, 1997.

[70] H. Brevinge, E. Lindholm, S. Buntzen, and J. Kewenter, "Screening for colorectal neoplasia with faecal occult blood testing compared with flexible sigmoidoscopy directly in a 55-56 years' old population," International Journal of Colorectal Disease, vol. 12, no. 5, pp. 291-295, 1997.

[71] A. Federici, C. Marinacci, M. Mangia, P. Borgia, P. Giorgi Rossi, and G. Guasticchi, "Is the type of test used for mass colorectal cancer screening a determinant of compliance?. A cluster-randomized controlled trial comparing fecal occult blood testing with flexible sigmoidoscopy," Cancer Detection and Prevention, vol. 30, no. 4, pp. 347-353, 2006.

[72] G. Gondal, T. Grotmol, B. Hofstad, M. Bretthauer, T. J. Eide, and G. Hoff, "The Norwegian Colorectal Cancer Prevention (NORCCAP) screening study: baseline findings and implementations for clinical work-up in age groups 50-64 years," Scandinavian Journal of Gastroenterology, vol. 38, no. 6, pp. 635-642, 2003.

[73] D. Lisi, C. Hassan, M. Crespi, and A. S. Group, "Participation in colorectal cancer screening with FOBT and colonoscopy: an Italian, multicentre, randomized population study. [Erratum appears in Dig Liver Dis. 2012 Feb;44(2):182 Note: Hassan, C Cesare [corrected to Hassan, Cesare]]," Digestive and Liver Disease, vol. 42, no. 5, pp. 371-376, 2012.

[74] Multicentre Australian Colorectal-neoplasia Screening (MACS) Group, "A comparison of colorectal neoplasia screening tests: a multicentre community-based study of the impact of consumer choice," Medical Journal of Australia, vol. 184, no. 11, pp. 546-550, 2006.

[75] E. Quintero, A. Castells, L. Bujanda et al., "Colonoscopy versus fecal immunochemical testing in colorectal-cancer screening," The New England Journal of Medicine, vol. 366, no. 8, pp. 697706, 2012.

[76] M. Rasmussen, O. Kronborg, C. Fenger, and O. D. Jørgensen, "Possible advantages and drawbacks of adding flexible sigmoidoscopy to hemoccult-II in screening for colorectal cancer. A randomized study," Scandinavian Journal of Gastroenterology, vol. 34, no. 1, pp. 73-78, 1999.

[77] N. Segnan, C. Senore, B. Andreoni et al., "Randomized trial of different screening strategies for colorectal cancer: patient response and detection rates," Journal of the National Cancer Institute, vol. 97, no. 5, pp. 347-357, 2005.

[78] N. Segnan, C. Senore, B. Andreoni et al., "Comparing attendance and detection rate of colonoscopy with sigmoidoscopy and FIT for colorectal cancer screening," Gastroenterology, vol. 132, no. 7, pp. 2304-2312, 2007.

[79] J. E. C. W. Verne, R. Aubrey, S. B. Love, I. C. Talbot, and J. M. A. Northover, "Population based randomised study of uptake and yield of screening by flexible sigmoidoscopy compared with screening by faecal occult blood testing," British Medical Journal, vol. 317, no. 7152, pp. 182-185, 1998.
[80] A. G. Zauber, S. J. Winawer, G. M. Mills et al., "Adherence to screening in a randomized controlled trial of a one-time screening colonoscopy versus program of annual fecal occult blood test (gFOBt): implications of lower gFOBt adherence to screening on colorectal cancer mortality reduction," Gastroenterology, vol. 142, no. 5, pp. S82-S83, 2012.

[81] A. H. C. van Roon, S. L. Goede, M. van Ballegooijen et al., "Random comparison of repeated faecal immunochemical testing at different intervals for population-based colorectal cancer screening," Gut, vol. 62, no. 3, pp. 409-415, 2013.

[82] B. J. Shea, J. M. Grimshaw, G. A. Wells et al., "Development of AMSTAR: a measurement tool to assess the methodological quality of systematic reviews," BMC Medical Research Methodology, vol. 7, article 10, 7 pages, 2007.

[83] G. A. Wells, B. Shea, D. O'Connell et al., The NewcastleOttawa Scale (NOS) for Assessing the Quality of Nonrandomised Studies in Meta-Analyses, Ottawa Hospital Research Institute, Ottawa, Canada, 2012, http://www.ohri.ca/programs/clinical_ epidemiology/oxford.htm.

[84] P. Whiting, A. W. S. Rutjes, J. B. Reitsma, P. M. M. Bossuyt, and J. Kleijnen, "The development of QUADAS: a tool for the quality assessment of studies of diagnostic accuracy included in systematic reviews," BMC Medical Research Methodology, vol. 3, article 25, 2003.

[85] J. Brożek, A. Nowak, P. Kunstman, and H. J. Schünemann, GRADEpro Guideline Development Tool (G2DT), (Computer Program) Version 2.xx, 2014, http://www.guidelinedevelopment.org.

[86] Review Manager (Rev Man). 4.2 for Windows, The Nordic Cochrane Centre, The Cochrane Collaboration, Copenhagen, Denmark, 2003.

[87] B. J. Elmunzer, R. A. Hayward, P. S. Schoenfeld, S. D. Saini, A. Deshpande, and A. K. Waljee, "Effect of flexible sigmoidoscopybased screening on incidence and mortality of colorectal cancer: a systematic review and meta-analysis of randomized controlled trials," PLoS Medicine, vol. 9, no. 12, Article ID e1001352, 2012.

[88] P. Hewitson, P. Glasziou, L. Irwig, B. Towler, and E. Watson, "Screening for colorectal cancer using the faecal occult blood test, Hemoccult," Cochrane Database of Systematic Reviews, no. 1, Article ID CD001216, 2011.

[89] N. J. Massat, S. M. Moss, S. P. Halloran, and S. W. Duffy, "Screening and primary prevention of colorectal cancer: a review of sex-specific and site-specific differences," Journal of Medical Screening, vol. 20, no. 3, pp. 125-148, 2013.

[90] Canadian Task Force on Preventive Health Care, "Recommendations on screening for breast cancer in average-risk women aged 40-74 years," Canadian Medical Association Journal, vol. 183, no. 17, pp. 1991-2001, 2011.

[91] R. Sankaranarayanan, B. M. Nene, S. S. Shastri et al., "HPV screening for cervical cancer in rural India," The New England Journal of Medicine, vol. 360, no. 14, pp. 1385-1394, 2009.

[92] T. André, C. Boni, M. Navarro et al., "Improved overall survival with oxaliplatin, fluorouracil, and leucovorin as adjuvant treatment in stage II or III colon cancer in the MOSAIC trial," Journal of Clinical Oncology, vol. 27, no. 19, pp. 3109-3116, 2009.

[93] B. Levin, D. A. Lieberman, B. McFarland et al., "Screening and surveillance for the early detection of colorectal cancer and adenomatous polyps, 2008: a joint guideline from the American cancer society, the US multi-society task force on colorectal cancer, and the American college of radiology," Gastroenterology, vol. 134, no. 5, pp. 1570-1595, 2008. 
[94] Scottish Intercollegiate Guidelines Network (SIGN), Diagnosis and Management of Colorectal Cancer. A National Clinical Guideline, SIGN Publication no. 126, Scottish Intercollegiate Guidelines Network (SIGN), Edinburgh, UK, 2011.

[95] European Commission, European Guidelines for Quality Assurance in Colorectal Cancer Screening and Diagnosis, Edited by N. Segnan, J. Patnick, L. von Karsa, Publications Office of the European Union, Rue Mercier, Luxembourg, 1st edition, 2010.

[96] U.S. Preventive Services Task Force, "Screening for colorectal cancer: U.S. Preventive Services Task Force recommendation statement," Annals of Internal Medicine, vol. 149, no. 9, pp. 627637, 2008.

[97] D. Leddin, "The Canadian Association of Gastroenterology position on colon cancer screening," Canadian Journal of Gastroenterology, vol. 17, no. 2, p. 133, 2003.

[98] D. K. Rex, D. A. Johnson, J. C. Anderson et al., "American College of Gastroenterology guidelines for colorectal cancer screening," The American Journal of Gastroenterology, vol. 104, no. 3, pp. 739-750, 2009.

[99] Canadian Task Force on Preventive Health C, "Recommendations on screening for colorectal cancer in primary care," Canadian Medical Association Journal, vol. 188, no. 5, pp. 340348, 2016.

[100] US Preventive Services Task Force, "Screening for colorectal cancer: us preventive services task force recommendation statement," The Journal of the American Medical Association, vol. 315, no. 23, pp. 2564-2575, 2016.

[101] C. Dubé, “Tackling colorectal cancer as a public health issue: what can the gastroenterologist do?" Canadian Journal of Gastroenterology, vol. 26, no. 7, pp. 417-418, 2012. 


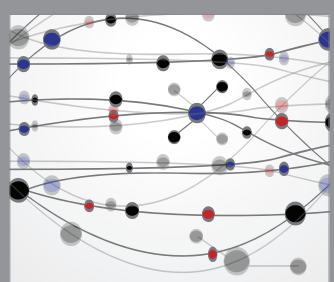

The Scientific World Journal
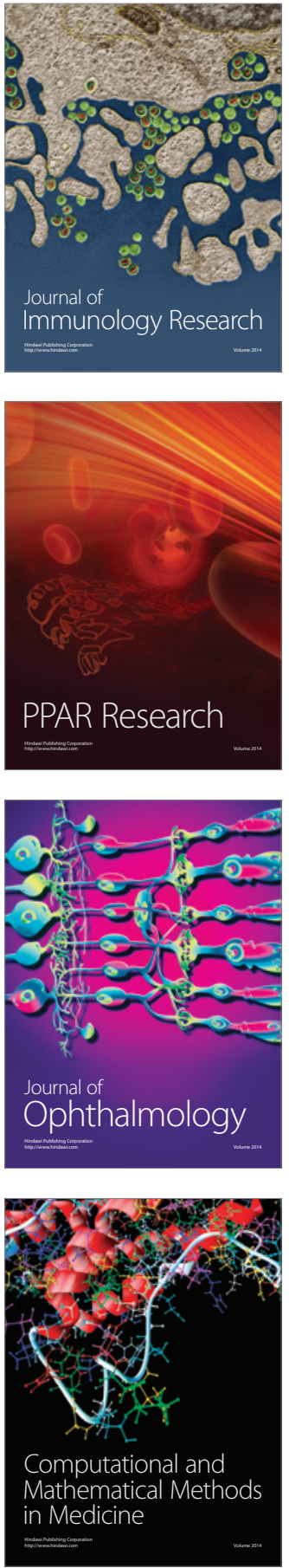

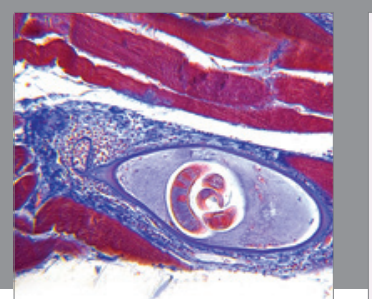

Gastroenterology Research and Practice

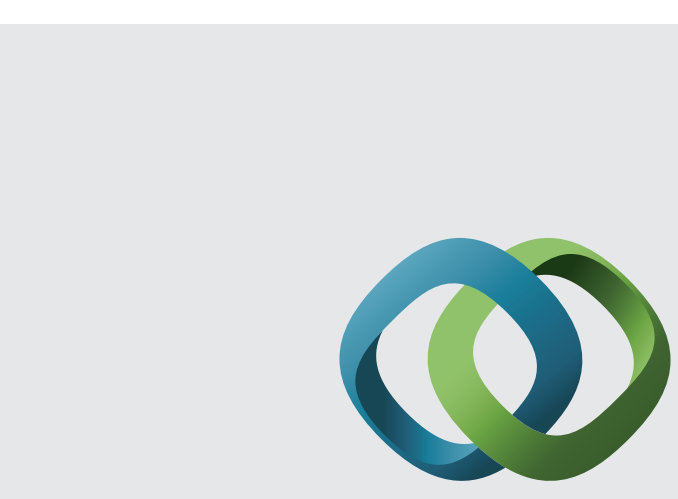

\section{Hindawi}

Submit your manuscripts at

http://www.hindawi.com
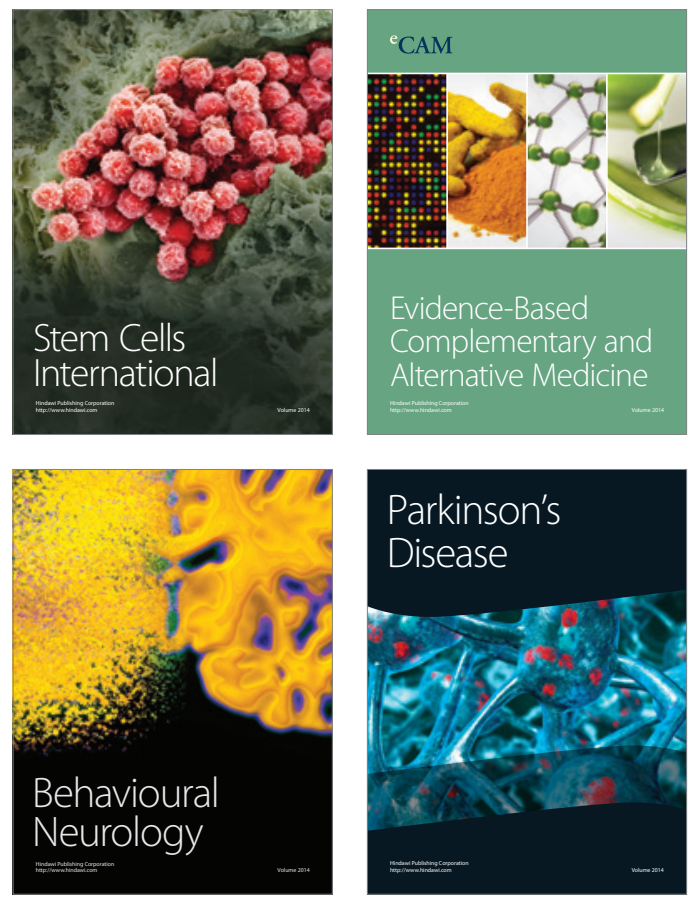
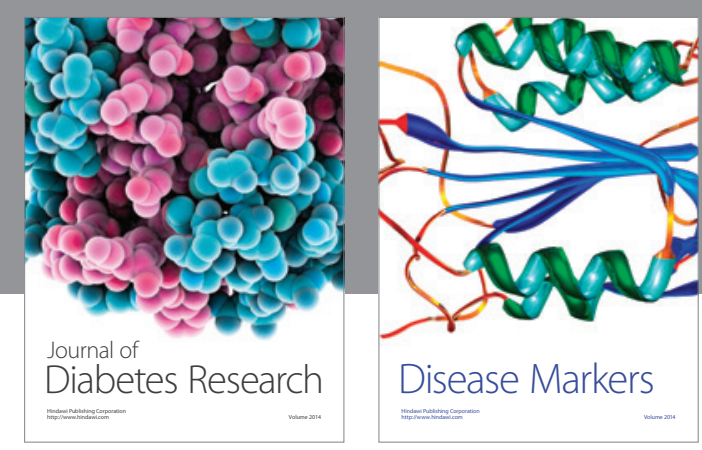

Disease Markers
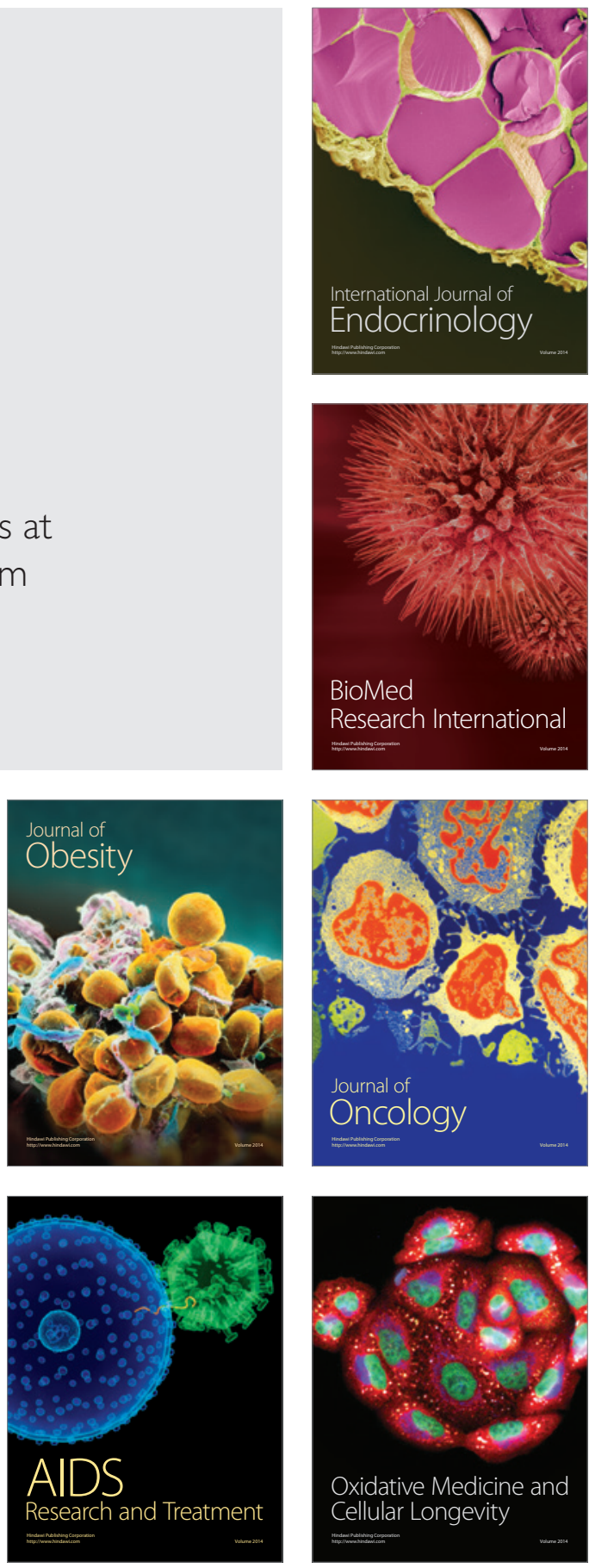